ANTUNES, Marília Mattos (...) USP - Ano X, n. I5, p. 157-165, 2019

\title{
Um novo olhar sobre os conflitos rurais no Chile nas décadas de 1960 e 1970
}

\section{Marília Mattos Antunes}

Mestra em História Social pela Universidade de São Paulo (USP)

\section{Resenha \\ REDONDO, Jesús-Ángel. Tierra, trabajo y libertad. Conflictos campesinos e indígenas en la provincia de Cautín (1967-1973). Santiago: LOM Ediciones, 2017. Livro em formato digital.}

Palavras-chave conflitos fundiários, reforma agrária, Cautín.

Keywords land conflicts, land reform, Cautín. 


\section{R E V I S TA A N G E L U N O V U S}

$\Lambda_{\text {tema relativo à estrutura fundiária e aos conflitos no campo na América Latina parece }}$ não se esgotar. Para além do surgimento de novos enfoques, que renovam debates ao lançar luz sobre problemáticas antes relegadas a um segundo plano ou até mesmo silenciadas, não podemos ignorar que o destaque até hoje conferido à temática deve-se, em grande medida, à persistência incômoda e expressiva, na atualidade, de confrontos violentos no campo em países latino-americanos. ${ }^{1}$

No caso chileno, há um volume significativo de trabalhos que se dedica a discutir os conflitos rurais e os atores sociais envolvidos em tais disputas. Salta aos olhos o grande número de pesquisas que aborda o movimento camponês, os conflitos no campo e os debates em torno da reforma agrária durante as turbulentas décadas de 1960 e 1970, e não à toa: foi precisamente nesse período que a pauta ganhou centralidade no debate público, tendo sido incorporada aos programas de governo de partidos de grande projeção no cenário político chileno, tais como Partido Nacional, a Democracia Cristã e a Unidade Popular. ${ }^{2}$

O trabalho de Jesús-Ángel Redondo, intitulado Tierra, trabajo y libertad. Conflictos campesinos e indigenas en la provincia de Cautín (1967-1973), publicado em 2017, vem somar esforços ao conjunto de pesquisas que procura compreender as múltiplas facetas dos conflitos no campo durante as efervescentes décadas de 1960 e 1970. A obra, resultado do projeto de investigação de pós-doutorado realizado na Universidade de Santiago de Chile, centra-se na

I De acordo com o relatório Defender la tierra - Asesinatos globales de defensores/as de la tierra y el medio ambiente en 2016, produzido pela organização internacional Global Witness, 60\% dos assassinatos de defensores de causas ambientais e reforma agrária ocorreram na América Latina. Segundo o órgão, o "Brasil se mantiene como el país más mortífero según el número total de muertes, mientras que Nicaragua es el peor lugar considerando la cantidad de asesinatos per cápita. Durante la última década, Honduras mantuvo su estatus como el lugar más peligroso, tomando como indicador la cantidad de asesinatos per cápita durante los últimos io años.” De acordo com o relatório, em 2016 ocorreram cerca de 200 assassinatos, sendo 49 no Brasil, 37 na Colômbia, I4 em Honduras, ı na Nicarágua e 6 na Guatemala. GLOBAL WITNESS. Defender la tierra: Asesinatos globales de defensores/as de la tierra y el medio ambiente en 2oI6. Inglaterra, 20I7, p. 7, II.

2 É o que mostra a obra La tierra y el poder. Reforma agraria en Chile (1967-1973), de Arturo Aldunate. O autor aponta que apesar de ter tido espaço na campanha eleitoral da Frente Popular, que subiu ao poder em 1938, a questão agrária acabou perdendo força diante da clara prioridade concedida pelo governo de Pedro Aguirre Cerda à industrialização. Foi na década de 1960 que a pauta voltou com novo fôlego, impulsionada pelo aumento de conflitos no campo e também pelo fortalecimento de uma perspectiva que via como urgente a necessidade de reformar a estrutura fundiária chilena a fim de solucionar problemas como a baixa produtividade do meio agrícola e o intenso êxodo rural motivado pela crise no campo. Nesse contexto, havia ainda a preocupação com uma possível radicalização dos movimentos populares de luta por reforma agrária, temor compartilhado pelo governo de John Kennedy, que no contexto polarizado da Guerra Fria impulsionou o programa conhecido como "Aliança para o progresso", com o intuito de estimular reformas (entre elas a agrária e habitacional) a fim de diminuir descontentamentos e evitar um crescimento do ideário socialista na América Latina. Para mais detalhes, ver: FONTAINE ALDUNATE, Arturo. La tierra y el poder: Reforma agraria en Chile (1964-1973). Santiago: Editora Zig Zag, 200 . 
ANTUNES, Marília Mattos (...) USP - Ano X, n. I5, p. 157-165, 2019

discussão das diferentes modalidades de protesto e rebeldia camponesa e indígena ocorridas na província de Cautín, abarcando os períodos dos governos do democrata cristão Eduardo Frei Montalva e de Salvador Allende Gossens, líder da coalizão de esquerda Unidade Popular.

A opção do autor por este recorte temporal deve-se ao fato de as décadas de 1960 e I970 terem sido marcadas por um crescente protagonismo das massas dentro do debate político e por importantes transformações no campo chileno, impulsionadas por leis criadas no referido contexto, tais como a Lei de Sindicalização Camponesa e a Lei de Reforma Agrária, ambas de 1967. Para Redondo, tais leis foram responsáveis por promover uma mudança nas relações sociopolíticas do campo chileno e estimularam a generalização e o aumento das mobilizações de trabalhadores agrícolas e dos indígenas mapuche no período destacado.

O estudo de Jesús-Ángel Redondo, nesse sentido, dialoga com trabalhos que se centraram na discussão e análise da relação entre as políticas voltadas para o campo, os conflitos agrários e os levantes camponeses no Chile, parte significativa deles produzida na década de 1970, caso da obra de Kyle Steenland, intitulada Agrarian Reform under Allende: peasant revolt in the Soutb3, e do artigo "Agrarian Reform and Rural revolution in Allende's Chile”, de Peter Winn e Cristóbal Klay4. Faz-se necessário destacar, entretanto, que a despeito de reconhecer a relevância destes trabalhos, o autor ressalva que boa parte deles, pautada no pressuposto teórico marxista da luta de classes, muito em voga no período, produziu "una visión estática y monolítica de los conflitos sociales campesinos, asimilando los mismos a los protagonizados por el proletariado industrial."s

Em sua visão, as obras desse contexto acabaram simplificando os complexos e múltiplos aspectos dos conflitos no campo ao reduzir os atores neles envolvidos a dois papéis antagônicos (camponeses versus patrões) e ao atribuir a estes pares opostos uma ideologia muito precisa e bem delimitada (revolucionária versus conservadora, respectivamente). ${ }^{6}$

Tendo essa problemática em vista, a pesquisa de Jesús-Ángel Redondo se vincula a trabalhos mais recentes que mostram que não houve uma confluência constante e linear entre os levantes camponeses e o movimento operário, e que destacam o caráter heterogêneo das demandas e dos atores sociais envolvidos nesses processos, como é o caso da obra

3 STEENLAND, Kyle apud REDONDO, Jesús-Ángel. Tierra, trabajo y libertad: Conflictos campesinos e indígenas en la provincia de Cautín (1967-1973). Santiago: LOM Ediciones, 2017. Livro em formato digital, n.p.

4 WINN, Peter; KLAY, Cristóbal apud REDONDO, Jesús-Ángel, op. cit., n.p.

5 REDONDO, Jesús-Ángel, op. cit., n.p.

6 Ibidem, n.p 


\section{R E VISTA A N G E L S N O V U S}

"Campesinos rebeldes. La lucha del campesinato entre la modernización y la globalización”, de Óscar Bascuñán Añover.7

Já em relação ao recorte espacial, há uma dupla justificativa para a escolha da província de Cautín por Redondo. A primeira se assenta no fato de que esta região foi um dos principais focos de conflitos rurais no Chile entre 1967 e 1973, além de ter contado com a presença de grupos camponeses revolucionários, tais como o Movimiento Campesino Revolucionario, ligado ao MIR. A segunda, por sua vez, deve-se à escolha metodológica do autor de adotar uma perspectiva local/ regional de análise, a fim de fugir de leituras totalizantes que, utilizando somente documentação de âmbito nacional, acabaram por ocultar particularidades que ajudam a melhor compreender o caráter complexo e múltiplo dos conflitos no campo ocorridos no Chile. ${ }^{8}$

Observa-se, aqui, uma crítica direta de Redondo ao trabalho de Susana Bruna, intitulado Chile: las luchas campesinas en el siglo $X X$, já que baseando sua análise exclusivamente em dados produzidos por instituiçóes governamentais para investigar o fenômeno das tomas de fundo no Chile, Bruna chega à cifra de 169 ocupações entre 1967 a 1971, enquanto Redondo, ao mobilizar periódicos provinciais, crava a cifra de um total de 234 ocupações em Cautín no mesmo período. ${ }^{9}$ A partir da constatação dessa discrepância, o autor consegue justificar a relevância de seu trabalho ao afirmar a necessidade de pesquisas de caráter local a fim de lançar luz sobre a verdadeira dimensão e o caráter heterogêneo das ocupações no Chile.

Ainda em relação ao debate historiográfico, é relevante destacar as interlocuções que o autor estabelece com obras mais recentes que se dedicaram à discussão dos aspectos identitários das ocupações e dos levantes camponeses no Chile. Nesse sentido, merecem menção os trabalhos La sangre del copibue. La comunidade mapuche de Nicolás Ailió y el Estado Chileno, 1906-200 I ${ }^{\mathrm{10}}$, de Florencia Mallon, e La reforma agraria y las tierras mapuches. Chile, 1962-1975, de Martín Correa, Raúl Molina e Nancy Yáñez."

De acordo com Redondo, essas obras colocam novas questões e problemáticas sobre os conflitos no campo ao se debruçarem sobre a dimensão étnica desses levantes e de como as políticas agrárias afetaram esses povos. Entretanto, aponta que tais estudos têm uma limitação por perderem a perspectiva de conjunto ao centralizar as análises em apenas um grupo (étnico ou de gênero).

7 BASCUÑÁN AÑOVER, Óscar apud REDONDO, Jesús-Ángel, op. cit., n.p.

8 REDONDO, Jesús-Ángel, op. cit., n.p.

9 Ibidem, n.p.

Io MALLON, Florencia apud REDONDO, Jesús-Ángel, op. cit., n.p.; REDONDO, Jesús-Ángel, op. cit., n.p. CORREA, Martín; MOLINA, Raúl; YÁÑEZ, Nancy apud REDONDO, Jesús-Ángel, op. cit., n.p. 
ANTUNES, Marília Mattos (...) USP - Ano X, n. I5, p. 157-165, 2019

Dividida em cinco capítulos, a obra de Redondo tem como objetivo central "mostrar el dinamismo y la complejidad de la conflictividad rural y de los sujetos que participaron en la misma." ${ }_{\text {г2 }}$ Para tal, ele mobiliza um conjunto amplo e variado de fontes, composto por periódicos locais (com destaque para El Diario Austral), documentos produzidos pelo governo provincial (boletins, informes, ofícios), e testemunhos orais de vários dos envolvidos nos conflitos rurais naqueles anos (políticos e militantes de diferentes partidos, dirigentes sindicais e integrantes de movimentos sociais e organizações camponesas).13

A partir desse corpus documental, o autor evidencia a heterogeneidade dos conflitos do campo naqueles anos por meio da análise de vários aspectos: os atores envolvidos no processo, a natureza diversa das reivindicações produzidas, as diferentes estratégias de luta mobilizadas, bem como o papel e o grau de influência de organizações políticas provinciais e nacionais nas lutas no campo. Através do cruzamento desses elementos, Redondo consegue demonstrar as particularidades dos conflitos cautinenses sem, no entanto, deixar de lado suas conexões com o cenário político chileno mais geral.

O pesquisador centra sua atenção na análise de três expressões de protesto camponês e indígena: o cuatrerismo (prática de roubar gado, que pode ser traduzida como abigeato), as ocupações ilegais de terras (tomas de fundos), e as estratégias de luta ensejadas pelo sindicalismo camponês (greves e petições públicas, em especial).

O percurso para a discussão das especificidades de cada uma dessas modalidades de protesto se inicia com uma apresentação dos antecedentes históricos da província de Cautín no primeiro capítulo. Nele, o autor evidencia como a ocupação da região da Araucanía por meio de uma campanha militar entre os anos de I86I a I883 foi responsável por alterar a estrutura socioeconômica que existia até então ao promover a expropriação e divisão das terras pertencentes aos indígenas, gerando crise social, concentração de terra nas mãos de poucos e o consequente empobrecimento de indígenas e camponeses não-proprietários, que passaram a viver a níveis de subsistência. ${ }^{14}$

Segundo o autor, a região da Araucanía tem sua história permeada por episódios de violência e conflito, como atestam o processo de colonização e de incorporação de territórios dominados pelos indígenas ao Estado chileno. Os conflitos que ocorreram no campo entre as

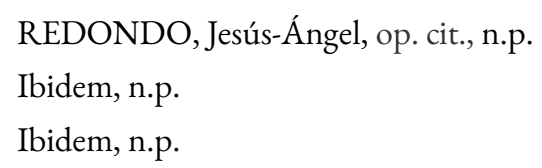




\section{R E V I S T A A N G E L S N O V U S}

décadas de 1960 e 1970 não são, portanto, descolados destes antecedentes históricos que fizeram com que as relações cotidianas da província fossem permeadas por violência. ${ }^{\text {Is }}$

Feita essa discussão, no capítulo seguinte, intitulado "El contexto político y social del campo chileno na década de 1960", Redondo reflete sobre a forma como as legislações voltadas a questões do mundo rural produzidas no contexto impactaram as relaçóes sociopolíticas no campo chileno e foram responsáveis por impulsionar uma onda de protestos camponeses e indígenas. Destaca, ainda que a província de Cautín foi um palco especial de tais levantes, já que ali verificou-se uma onda de tomas de fundo e também de conflitos mapuches como não se via desde a época da ocupação militar da Araucanía.

De acordo com o autor, as reformas eleitorais de 1958 criaram mecanismos para reduzir significativamente as fraudes eleitorais e possibilitaram uma inserção mais efetiva do eleitorado de origem rural, o que levou partidos de grande projeção do período a incorporarem em seus programas de governo propostas voltadas ao mundo agrícola.

Ao longo do capítulo, são comparados os diferentes programas formulados em torno da questão agrária, e debate-se o impacto que a Lei de sindicalização camponesa e a Lei de reforma agrária tiveram: a primeira, não só por legalizar a formação de sindicatos camponeses mas também por criar condições que facilitavam sua materialização e promover um aumento expressivo no número dessas organizações em Cautín; e a segunda, por ter impulsionado a expropriação de 3 milhões e 5,8 milhões de hectares durante os governos de Frei e Allende respectivamente, alterando significativamente o desenho da estrutura fundiária no país. ${ }^{16}$

Discute-se ainda, a conformação de novas organizações destinadas à luta por reforma agrária e melhoria nas condições de vida e trabalho no campo, muitas delas vinculadas a partidos políticos, tais como a Federación Provincial de Trabajadores Agricolas Presidente Frei, ligada ao Partido Democrata Cristão, a Federación Provincial de Sindicatos de Trabajadores Agricolas y Mapuches Luis Emilio Recabarren, do Partido Comunista, e o Movimiento Revolucionario Campesino (MCR), associado ao MIR (Movimiento Izquierda Revolucionária).

Já no terceiro capítulo, são analisadas detidamente as variadas modalidades de protesto que tiveram lugar na província de Cautín, havendo grande preocupação por parte do autor em ressaltar as especificidades dos conflitos cautinenses em relação a outras áreas do Chile. Justamente nesse capítulo encontram-se as principais contribuições de Redondo ao debate historiográfico acerca dos conflitos do campo no Chile. 
ANTUNES, Marília Mattos (...) USP - Ano X, n. I5, p. 157-165, 2019

A respeito do cuatrerismo, por exemplo, o autor aponta que trata-se de uma expressão de rebeldia camponesa existente desde os tempos coloniais, e que embora pesquisas demonstrem um declínio dessa prática entre as décadas de 1920 e 1930, na década de 1960 esta atividade preocupava agricultores e autoridades e tinha destaque nos periódicos locais devido aos enfrentamentos violentos dela decorrentes. ${ }^{17}$

Ao analisar as características do cuatrerismo na província, Redondo assinala sua ligação com outras atividades ilícitas, tais como o contrabando de animais para a Argentina e o comércio ilegal de carne através dos matadouros clandestinos, além de verificar que a grande participação de mapuches nessa modalidade de rebeldia advém de sua condição de marginalização socioeconômica, conferindo ao cuatrerismo cautinense um peculiar caráter de subsistência.

Já no que diz respeito ao sindicalismo, o autor salienta que esta expressão de fato tomou fôlego e se generalizou na província a partir da década de 1960, seguindo uma tendência que se verificava em todo o país, suscitada pela nova legislação de sindicalização camponesa.

A despeito dessa confluência, Redondo verifica que ao contrário das áreas mais centrais do Chile, onde predominou um sindicalismo vinculado a organizações de esquerda e onde a greve manifestou-se como o instrumento de luta por excelência, em Cautín houve um forte protagonismo dos sindicatos ligados à Democracia Cristã e, por isso, observa-se na área uma opção clara pela via institucional como meio negociação e resolução de conflitos, a partir da apresentação de petições coletivas. ${ }^{18}$

Já em relação às tomas de fundo ou ocupações ilegais, as contribuições da obra de Redondo são ainda mais notáveis. Seu estudo refuta as perspectivas que apontam para uma hegemonia da ação indígena nessa modalidade de protesto, bem como rechaça a ideia de que os conflitos territoriais em Cautín foram majoritariamente impulsionados por organizações de caráter revolucionário como o já citado MCR, apesar da marcante presença do grupo na região.

A partir da análise de periódicos e de consultas em arquivos provinciais, Jesús-Ángel Redondo aponta que $45 \%$ das tomas registradas em Cautín não foram impulsionadas ou influenciadas por nenhum tipo de organização revolucionária. Nesse sentido, defende que o processo de conscientização de camponeses e indígenas não deveu-se apenas à ação de propaganda realizada por organizações políticas, mas pela difusão de debates políticos em 


\section{R E VISTA A N G E L U N O V U S}

torno das reformas por meio de imprensa e do rádio, que desencadeou um processo que o autor chama de "autoconscientização".19

Observa, ainda, que no caso das tomas em Cautín, há um equilíbrio entre as ocupações ilegais realizadas por indígenas da etnia mapuche e por camponeses criollos, mas que são diversas as motivações que impulsionaram esses grupos a optarem por essa forma de protesto: enquanto os primeiros objetivam a restituição das terras usurpadas de seus antepassados, o que conferiria um caráter étnico-social às tomas, os segundos viam as ocupações ilegais como um instrumento de pressão para acelerar a política de reforma agrária, obter melhores condições de vida e até mesmo trabalho.

Apesar da ênfase conferida na obra à atuação de camponeses e indígenas nos conflitos rurais em Cautín, faz-se necessário salientar que Jesús-Ángel Redondo dedica uma parte de seu livro à reação dos proprietários agrícolas à onda de protestos verificados no período.

No capítulo 4, o pesquisador evidencia o perfil heterogêneo dos proprietários de terra que integravam as confederações e sindicatos de empregadores agrícolas no Chile, que englobava desde latifundiários até pequenos proprietários, e discute como a aliança entre esses grupos foi fundamental para a conformação de petições e a articulação de uma pressão sobre as autoridades visando à limitação da reforma agrária e o uso da força policial para sufocar conflitos no campo.

Ademais, o autor preocupa-se também em demonstrar a diversidade das ações políticas utilizadas pelos proprietários de terra a fim de combater a política agrária em curso e as revoltas camponesas e indígenas que se intensificavam nas décadas de 1960 e 1970, revelando que apesar do número de enfrentamentos ter sido pequeno, quando estes ocorreram resultaram em mortes e um número significativo de feridos.

Por fim, o quinto e último capítulo discute como a polarização político-ideológica e a escalada de violência verificadas no Chile no final do governo de Salvador Allende impactaram a província de Cautín, com destaque para as ações de revista realizadas por policiais e militares em organizações camponesas e sindicatos vinculados à esquerda, um prenúncio da violência e repressão que recairia sobre camponeses e indígenas a partir do golpe de 1973.

A partir do exposto, nota-se que a obra de Jesús-Ángel Redondo traz importantes contribuições ao cruzar elementos variados que muitas vezes são tomados de maneira isolada por algumas pesquisas. Ao realizar o esforço de entrelaçar diferentes modalidades de conflito no campo, os distintos atores envolvidos no processo e seus respectivos interesses, o autor 
ANTUNES, Marília Mattos (...) USP - Ano X, n. I5, p. 157-165, 2019 consegue evidenciar as particularidades das lutas no campo em Cautín, ao mesmo tempo em que atesta o caráter plural e complexo dos conflitos fundiários no Chile. Concluímos, portanto, que por meio da análise dos conflitos cautinenses, Redondo mostra as possibilidades abertas pela perspectiva de uma história local que não perde de vista os diálogos com o contexto nacional mais amplo.

Recebido: 07/09/2019 Aceito: 30/10/2019 